\title{
The Level of Satisfaction with Family Life and Self-Satisfaction among a Sample of Syrian Refugees in Jordan
}

\author{
Nashat Abu Hassouneh ${ }^{1} \&$ Ahmad Rasheed Zeiadeh ${ }^{2}$ \\ ${ }^{1}$ Dean Faculty of educational studies, Irbid National University, Jordan \\ ${ }^{2}$ Department of Physiological Counseling, Irbid National University, Jordan \\ Correspondence: Nashat Abu Hassouneh, Dean Faculty of educational studies, Irbid National University, Jordan. \\ E-mail: nabuhassouneh@yahoo.com
}

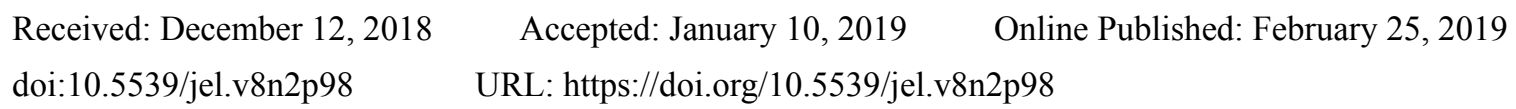

\begin{abstract}
This study aims to identify the level of satisfaction with family life and self-satisfaction among sample of Syrian refugees in Jordan in the light of some variables. The study consisted of 427 Syrian refugees. The result shows an average level of satisfaction with family life and self-satisfaction. In addition, it indicates that there are statistically significant differences in the satisfaction with the family life and self-satisfaction according to the following variables: gender in the favor of females. Moreover, the results show differences in the level of satisfaction with family life according to the age variable in the favor of less than 15 years, and there are differences in the level of self-satisfaction according to the age variable in the favor of 16-30 years and 31-45 years.
\end{abstract}

Keywords: satisfaction with family life, self-satisfaction, Syrian refugees, Jordan

\section{Introduction}

The family is the most important source in supporting its members. It works to achieve many aspects of life, especially psychological and social, and works to provide maximum security and balance. Relations between family members are the most important sources of internal satisfaction and satisfaction with life. Coherence and adaptability to the family system, but individuals often face personal, social, academic or economic stress, and those who face these difficulties are refugees. Syrian refugee families in Jordan are suffering from increasing economic and social pressures, especially those are scattered because of the presence of mother and children in a place far from the father, often the father and mother remain single, while the children are distributed in different countries, which makes hope of reunion again almost impossible, especially when member s of the family are detained and may have unknown fate, in addition to the difficult living conditions and security measures that facing these families. Therefore, dispersion of the family has a negative impact on the psychological side of the family (Al-Refai, 2017). So, migration has been the solution for many Syrian families, which led to internal changes for families, including:

1) Changes within the family: when the father or husband does not return and he is the breadwinner, so the state and the powers of asylum and social control beard the burden.

2) Asylum often leads to the inability of the father or husband and even the mother to deal with the new environment. This creates a cognitive gap reflected on the education within the family.

3) Loss of the "social safety net" that was traditional in the home environment, which is based on relatives, neighborliness, friendship and traditional fellowship, where they try to search for new relationships and social safety net but they will not be like the former (Al-Refai, 2017).

The number of Syrian refugees in Jordan registered with the commission reached 588.792 as of April 2014, while the actual number of Syrian refugees in Jordan is 1.3 billion. The Syrian refugees in Jordan can be divided into two categories: who lives inside the camps, and who lives outside it, as in other countries. It is clear that $20 \%$ of the Syrian refugees are currently living in the camps an 80\% live in Jordanian cities (Orkhan, 2014).

Some statistic indicates that more than 16 million people live as refugees in the world, according to the High Commissioner for refugees (UNHCR). More than 12 million adolescents live as refugees as a result of having to 
leave their country origin (Damrah \& Nassar, 2014). Adolescents suffer from physical and psychological problems because they experience conflict, distraction and violence directly which is may lead to long term effect (United Nations High Commissioner for Refugees, 2013). Syrian conflict has forced more than 4 million people to leave their country and it also forced 1.5 million others to seek refuge in neighboring countries. Starting from March 2013, Jordan has hosted more than 470,000 Syrian refugees, reached nearly 1.40 million, most of them women and children (UNHCR, 2014).

A refugee is someone who has been forced to flee his or her country because of persecution, war, violence, reasons of race, religion, nationality, political opinion or membership in a particular social group (Freihat, 2017).

\subsection{Satisfaction with Family Life}

Families are the primary source of individual development and the primary setting in which children begin to acquire their beliefs, attitudes, values and behaviors considered as appropriate to society (Ogwo, 2013). The White Paper on Families defines families as societal groups of members related by blood (kinship), adoption, foster care or ties of marriage (extended families), including civil, customary, or religious marriages, or communal union, and extends beyond any particular shared physical residence (Department of Social Development, 2013).

Families are guided by three key strategic priorities aimed at guiding the core functions of the family. These key priorities include: (1) focuses on the efforts preventing the breakdown of family life by promoting positive attitudes and values; (2) family strengthening refers to the deliberate process of giving families the necessary opportunities, relationships, networks, support and protection during times of adversity and social change; and (3) family preservation, which generally refers to keeping families together with specific programs intending to strengthen families during crises (Department of Social Development, 2013).

Families function provides a way of incorporating individuals into social life and it provides the source of emotional, influential and material support for its members and how they can communicate with each other, relate to one another, maintain relationships, and make decisions and solve problems together. As a result, family functioning can be seen as a multidimensional concept which denotes how family members interact with one another and collaborate in achieving a common goal and outcome (Botha \& Booysen, 2013). Family rituals such as interaction between individuals, love, maintaining close relationships, conflict resolution, provides emotional and social support all these are indicators of satisfaction with family life (Ramalho Lachal, Bucher-Malischke, Moro \& Revath-Levy, 2016).

Satisfaction is one of the most important elements of psychology, which describes this aspect of self-well-being from a personal and cognitive perspective, the cognitive aspect focuses on the process of simulation rather than on emotional experiences, either the personal aspect depends on the criteria determined by himself (Bernal \& Arocena, 2014).

Satisfaction with family life has a positive impact on impact health and quality of the life (Guillen et al., 2013). High level of satisfaction with family relationship is associated with the ability to adapt, communicate and feel good (Rozer, Mollenhorst, \& Poortman, 2016), because there is an effect for the family on emotional well-being that extends beyond the teenager; where the positive family relationship helps the individuals overcome the challenges of life and thus enhance their satisfaction with life (Thomson, Schoner-Reichl, \& Oberle, 2015).

Hilger, Loerbork and Diehl (2017) noted that female look for more support from their families and shows better relationships with their parents than male; therefore, they are more satisfied with their lives than male.

\subsection{Self-Satisfaction}

Self-satisfaction reflects the extent of the conviction of the person himself and his limits, the extent of his faith in what he achieved, and the acceptance of what he did not achieve. Satisfaction is not related to the individual's duties and responsibilities. Rather, it comes from the positive feeling of respect for each individual for all his or her abilities. The satisfaction is strongly linked to the concept of the individual, which is formed from childhood through proper parenting that meets the needs of the individual and develops spirit and self-satisfaction is linked to the satisfaction of the individual with the reality he lives in, and the formation of a relationship of coexistence and reconciliation with the world around him. The sense of anxiety and fear of being wrong, and the non-discrimination between the possible and the available, the accepted and the rejected misleads the concept of the individual positive about himself, and thus lose the ability to enjoy the advantages, and disrespectful satisfaction, as the sense of stability and clarity of ideas and the integrity of the individual achieve a high degree of Satisfaction and self-acceptance (Habib, 2015). 
People go through an existential crisis in which they try to fill the void by guiding themselves through conformity and tradition. Individuals do not use freedom to make their own choices in life until they find their meaning. Self-awareness, knowledge of emotions and motivation, a deep level of understanding, and knowledge of strengths and weaknesses are a tremendous source of self-satisfaction (Farooqi, 2012). Self-well-being is also one of the dimensions that involve positive emotional responses that influence judgments about satisfaction with life (Hsieh, 2016).

The results indicate that the degree of change within the individual in the degree of satisfaction is strongly influenced by the degree of success in the dimensions of individual satisfaction, and that the values contribute significantly to predicting the degree of self-well-being (Al-Nabaghah, 2012). Self-satisfaction has been identified as an essential feature of positive psychological performance (Ryff \& Singer, 2013)

Self-satisfaction is the feeling of absolute fulfillment with self and achievement, and simply the ability of the possible. Achieving self-satisfaction is not an easy task at all. There are many ways in which one can constantly search for self-satisfaction. In order to achieve self-satisfaction, a meaning must be created for life, which is achieved by experimenting with something, by engaging oneself in creative work, or by developing virtues such as compassion, courage, etc. (Farooqi, 2012). Self-satisfaction is the degree of satisfaction of the individual about himself, his achievements and the quality of life that he lives and distinguishes him from others. He is defined as linking the individual's ability and self-fulfillment (Fine Dictionary, 2017).

Karl Rogers points to congruence and conflict. Individuals have a real and ideal character. The very truth is what the individual is or can be (the real possibilities of the individual). The ideal self is the individual's sense of what it should be. Individuals tend to move towards the ideal self rather than the real self because of external expectations or pressure, and this gap between the real self and self-perfection is called by Rogers the contradiction. If there is no gap between the true self of the individual and the ideal self they call it congruence. If the gap between the two selves increases, the internal conflict and resentment increase, the individual feels threatened and worried, and thus the lack of self-satisfaction. Rogers summarizes his concept of the self and the dynamics that influence it through the following: the individual has a tendency to self-fulfillment and survival, as the individual lives in a constantly changing world, interacting with his cognitive field according to his experiences and feelings, and behavior is a deliberate attempt by the individual to satisfy his needs according to his experience in the field Which he understands, and the way the individual understands is to look at him as he sees himself and sees them, adopting patterns of behavior only in line with himself. Rogers also sees three important aspects of self-development in individuals: the need for positive consideration from others, the growing need for self-consideration, and the growth of conditions or conditions of maturity (Blanc, 2015).

Self-satisfaction is one of the most important keys to happiness because it makes a person in a stable state of mind. Whenever he has satisfaction with himself, he has satisfaction with others and all things, and vice versa. It is a state of inner acceptance in man that makes him at a level of psychological stability and makes him far from frustration and despair (Ryff \& Singer, 2013).

\subsection{Problem and Questions of the Study}

Refugees have many experiences which lead to mental disorders and unwillingness to communicate with others. Some find difficulty in facing challenges, loss of self-confidence and dissatisfaction, and despair of life leads to life without goals or meaning. There may be unexpected causes of self-hatred, in addition to difficult circumstances and family instability.

This study is considered one of the first studies that dealt with the satisfaction of family life in general and the life of Syrian refugees in particular. Hence, the problem of the study was to reveal the satisfaction with family life and self-satisfaction among sample of Syrian refuges in Jordan.

This study is trying to answer the following questions:

1) What is the level of satisfaction with the family life of the Syrian refugees in Jordan?

2) What is the level of the self-satisfaction of the Syrian refugees in Jordan?

3) Are there differences between the gender perceptions of Syrian refugees on the dimension of the scale of satisfaction with family life?

4) Are there differences between the gender perceptions of Syrian refugees on the dimension of the scale of self-satisfaction?

5) Are there statistically significant differences at the level of significance $(0.05 \geq \alpha)$ of satisfaction with family life due to the age? 
6) Are there statistically significant differences at the level of significance $(0.05 \geq \alpha)$ of self-satisfaction due to the age?

\subsection{Importance of the Study}

The importance of the study according to the theoretical perspective comes from the information that will be provided to specialists in the fields of psychology, especially the family and psychological fields. It also drew the attention of the UNHCR officials to the importance of self-satisfaction and satisfaction with family life as a part of the mental health of refugees. Thus, their satisfaction contributes to create a psychological healthy generation that performs its job efficiently and effectively.

On the other hand, the results of the study will help to design some educational and psychological programs that can contribute to raise the moral of the refugees and trained them. In addition, it will provide workers in the family and psychological fields with new measurement tools that will help them to measure satisfaction with family life and self-satisfaction. Also, this study may stimulate researchers to conduct new studies on samples from different environment.

\subsection{Aims of the Study}

This study aims to:

1) This study aims to identify the level of satisfaction with family life and self-satisfaction among sample of Syrian refugees in Jordan.

2) Identify differences in satisfaction with family life among sample of Syrian refugees in Jordan in the light of the following variables: gender and age.

3) Identify differences in self-satisfaction among sample of Syrian refugees in Jordan in the light of the following variables: gender and age.

\subsection{Limitation of the Study}

The scope of the study application is determined as follows:

- Limits of sample: the study was limited to a sample of Syrian refugees living in Irbid city.

- Place limits: this study was conducted in the northern Jordanian city of Irbid.

- Time limits: the study was carried out between November and December 2017.

- Objective limits: the results of the study are determined by the study tools, and the indications of validity. Thus, the results of the study can be generalized to communities similar to the study community only.

\subsection{Definitions}

Satisfaction with family life: is the extent to which family members feel happy and satisfied through the relationship of their members and the ease of communication between them (Zabriskie \& Ward, 2013). Procedural definition is the level which the student obtains a measure of satisfaction with the family life that is used in this study.

Self-satisfaction: It is the situation that creates an individual's inner acceptance and makes a level of selfstability away from what causes frustration (Ryff \& Singer, 2013). Procedural definition is the level which the student obtains a measure of self- satisfaction that is used in this study.

Syrian refugees: is someone who has been forced to flee his or her country because of persecution, war, violence, reasons of race, religion, nationality, political opinion or membership in a particular social group (Amnesty international, 2015). Procedurally can define as they are the persecuted individuals in their country Syria and reside in the city of Irbid.

First: Independent variables: gender (male/female), age divided into four categories (less than 15 years, 16-30 years, $31-45$ years, more than 46 years)

Second: Dependent variables: satisfaction with family life and self-satisfaction.

\section{Literature Review}

Schenettler et al. (2017) and others conducted a study on the relationship between satisfaction with family life and satisfaction with life in a sample of university students in Chile. The study consists of 370 students. The study shows correlation between satisfaction with life and satisfaction with family life, and a positive relationship between moral support and satisfaction with life. In addition, it shows that there were no gender differences. 
As for the study of Tasdelen-Karckay (2016) which aimed to adapt a measure of satisfaction with family life in a sample of Turkish adolescents. It consists of 506 adolescents. The results of the study show that internal consistency coefficients were high, with a general stability of 0.95 , while the correlation coefficients ranged between 0.75 and 0.48 .

Lopez-Ortega, Torres-Castro and Rosas-Carrasco (2016) evaluated the psychological characteristics of satisfaction with the measure of satisfaction with life in a sample of Mexican adults. This study consists of 13220 adults. The results show that the measure between the presences of internal consistency correlation coefficients was 0.74 , and the results of the analysis of variance explained $54 \%$, there was a relation between with a diagnostic significance associated with depression, health and social support.

Roman et al. (2016) pointed to the effect of family performance on the satisfaction of family members and the relationship between them. This study consists of 204 participants. The results show that the family may be at risk in terms of negative family performance, and the satisfaction with family life leads to social work.

As for the study of Zahao, Xu, Wang, Jiang and Zhang (2015) which aimed to identify the role of tension and conflict between parents and adolescences in China in the satisfaction of domestic adolescents and self-satisfaction. The sample of the study consists of 524 adolescents. The results show that tension and conflict were negatively associated with family satisfaction and self-satisfaction.

Bernal and Arocena (2014) were aimed to measure the satisfaction with family life among middle and high school students in Mexico. The study sample consists of 1395 students. The results show that there are statistically significant differences in the level of satisfaction with family life due to the gender variable among males and the existence of statistically significant differences in the level of satisfaction with family life due to the age from 11-16 years.

As for the study of Zabriskie and Ward (2013) which aimed to measure the level of satisfaction with the family life in a sample of parents which consists of 15 families. The results show that the level of satisfaction with family life varied between families, and the satisfaction with positive family life was associated with a healthy mental state.

The study of Ramesh, Sathian, Sinu and Kiranmai (2013) aims to identify the effect of the practice of mediation in positive thinking and happiness achieved for self-satisfaction. The study sample consist of 50 individuals divided into two groups. The results show that happiness levels were higher for meditative individuals and their level of self-satisfaction were higher than non-meditative.

In Rahim, Ishak, Shafia and Shafiai (2013) which aims to identify the factors that affect the satisfaction of family life among parents in Malaysia, the study sample consists of 2808 parents. The results of the study show that performance in family, and spent time with family had a significant and direct effect on satisfaction with the family life, with the exception of parental participation.

Calderon, Naranjo and Felpeto (2012) examined the woman's satisfaction with the average age and its impact on the quality of life. Sample study consists of 166 women. The results show that women who were satisfied with themselves were $18.07 \%$ with average $25.30 \%$.

\section{Methodology of the Study}

This study followed the descriptive analytical approach; it is evaluated the level of satisfaction with family life and self-satisfaction among to the Syrian refugees in the light of some variables. The study population consist of 144000 Syrian refugees residing in the city of Irbid northern Jordan of both gender in 2017. Total of 427 Syrian refugees were registered. They were selected in a randomly and availability way from the Syrians who living in Irbid in 2017. Table 1 shows the distribution of the study samples according to the study variables.

Table 1. Distribution of the study samples according to the study variables

\begin{tabular}{llll}
\hline Variables & Categories & Frequency & $\%$ \\
\hline gender & Male & 210 & $49 \%$ \\
& Female & 217 & $51 \%$ \\
\multirow{3}{*}{ Age } & Total & 427 & $100 \%$ \\
& Less than 15 year & 118 & $27 \%$ \\
& 16-30year & 127 & $30 \%$ \\
& 31-45 year & 101 & $24 \%$ \\
& More than 46 year & 81 & $19 \%$ \\
& Total & 427 & $100 \%$ \\
\hline
\end{tabular}




\section{First: a scale of satisfaction with family life}

The researcher referred to literature and previous studies on satisfaction with family life, such as Shnettler et al. (2017), Zabriskie and Ward (2013), Nua (2013) and Tasdelen-Karckay (2015), in order to prepare a scale of satisfaction with family life. The researcher verified the validity of the content by presenting the scale in its original form to a group of 8 arbitrators who are specialized in education and psychology at Irbid National University to insure that the appropriate elements of the scale for this category will be applied to the study. The arbitrators agreed on the validity of items by $80 \%$, and this percentage could be adopted for conducting the study The researcher also found the validity of the scale by applying it to a population of (62) from outside the study sample, and then calculating the values of the corrected correlation coefficients of each item with the total scale, as shown in Table 2 .

Table 2. The values of the corrected correlation coefficients for the scale items of satisfaction with family life

\begin{tabular}{llllll}
\hline NO & correlation coefficient & NO & correlation coefficient & NO & correlation coefficient \\
\hline 1 & 0.59 & 7 & 0.68 & 13 & 0.67 \\
2 & 0.74 & 8 & 0.53 & 14 & 0.53 \\
3 & 0.68 & 9 & 0.49 & 15 & 0.71 \\
4 & 0.47 & 10 & 0.61 & 16 & 0.60 \\
5 & 0.77 & 11 & 0.72 & & \\
6 & 0.65 & 12 & 0.55 & & \\
\hline
\end{tabular}

Table 2 shows that correlation coefficients ranged from 0.77 to 0.47 , all of them are statistically significant. The researcher adopted a criterion for acceptance of the item that the total of correlation coefficient of the dimension and the index are not less than 0.30 . The researcher verified the reliability of the scale in two ways: first by applying it to a sample of 62 refugees and the internal consistency coefficient was calculated Crnobach's Alpha, with a reliability value 0.82 . The researcher sees that this percentage could be adopted for conducting the study. As shown in Table 3.

Table 3. Reliability test

\begin{tabular}{lll}
\hline Scale & Crnobach's Alpha & Retest Reliability \\
\hline Academic self-regulation & 0.73 & 0.82 \\
\hline
\end{tabular}

The scale consists of 16 items, with Five Likert scale ( $1=$ never ever applicable, $2=$ not applicable, $3=$ neutral, $4=$ sometimes applicable, $5=$ strongly applicable), the grads from 16 to 80 , with a higher score indicating a high level of satisfaction with family life. The researcher referred to literature and previous studies related to self-satisfaction, such as the study of Zhao et al. (2015), Ramesh et al. (2013) and Calderon et al. (2012) in order to prepare the self-satisfaction scale. The researcher verified the validity of the content by presenting the scale in its original form to a group of 8 arbitrators who are specialized in education and psychology at Irbid National University to insure that the appropriate elements of the scale for this category will be applied to the study. The arbitrators agreed on the validity of items by $85 \%$, and this percentage could be adopted for conducting the study The researcher also found the validity of the scale by applying it to a population of 62 from outside the study sample, and then calculating the values of the corrected correlation coefficients of each item with the total scale, as shown in Table 4.

Table 4. The values of the corrected correlation coefficients for the scale items of satisfaction-satisfaction

\begin{tabular}{llllll}
\hline NO & correlation coefficient & NO & correlation coefficient & NO & correlation coefficient \\
\hline 1 & 0.71 & 7 & 0.66 & 13 & 0.71 \\
2 & 0.68 & 8 & 0.74 & 14 & 0.68 \\
3 & 0.49 & 9 & 0.50 & 15 & 0.49 \\
4 & 0.56 & 10 & 0.78 & 16 & 0.56 \\
5 & 0.62 & 11 & 0.67 & 17 & 0.62 \\
6 & 0.83 & 12 & 0.52 & 18 & 0.83 \\
\hline
\end{tabular}


Table 4 shows that correlation coefficients ranged from 0.83 to 0.49 , all of them are statistically significant. The researcher adopted a criterion for acceptance of the item that the total of correlation coefficient of the dimension and the index are not less than 0.30 .

The researcher verified the reliability of the scale in two ways: first by applying it to a sample of 62 refugees and the internal consistency coefficient was calculated Crnobach's Alpha, with a reliability value 0.78 . The researcher sees that this percentage could be adopted for conducting the study. As shown in Table 5.

Table 5. Reliability test

\begin{tabular}{lll}
\hline Scale & Crnobach's Alpha & Retest Reliability \\
\hline Academic self-regulation & 0.78 & 0.84 \\
\hline
\end{tabular}

The scale consists of 16 items, with Five Likert scale (1=never ever applicable, $2=$ not applicable, $3=$ neutral, $4=$ sometimes applicable, $5=$ strongly applicable), the grads from 18 to 90 , with a higher score indicating a high level of self-satisfaction. To achieve the objectives of the study, the tools of the study were prepared in its final form after verifying the indicators of its validity and stability, then the standards were distributed to the Syrian refugees in November of 2017, and gave them a general idea about the objectives of the study and its important, in addition that the instructions regarding the scale which is used are explained. For there more, they were assured that their participation was voluntary and the data they would provide would be treated with complete confidentiality and would be used for scientific research purposes.

To find out the level of both satisfaction with family life and self-satisfaction, the average and standard deviation were calculated, and to determine gender differences on the scale of both satisfaction with family life and self-satisfaction; T-test was used, while to determine the satisfaction with family life and self-satisfaction One Way ANOVA was used, in addition to Scheffe test for Post Hoc Comparisons.

\section{Findings}

The results of the study questions are presented below.

First question: What is the level of satisfaction with the family life of the Syrian refugees in Jordan?

To answer this question, the average and standard deviations were used for the level of satisfaction with family life among Syrian refugees in Jordan. As shown in Table 6.

Table 6. The average and standard deviations for the level of satisfaction with family life among Syrian refugees in Jordan descending according to the average

\begin{tabular}{|c|c|c|c|c|c|}
\hline Rank & No & Items & Average & Standard deviation & Level \\
\hline 1 & 3 & I am satisfied with the time that my family members spend with each other. & 3.63 & 1.03 & Middle \\
\hline 2 & 8 & I am satisfied with the communication skills between my family members. & 3.62 & 1.11 & Middle \\
\hline 3 & 16 & I am satisfied with degree of rapprochement between my family members & 3.60 & 1.01 & Middle \\
\hline 4 & 5 & I am satisfied with the level of caring between my family members & 3.57 & 1.14 & Middle \\
\hline 5 & 12 & I am satisfied with the relying of my family members & 3.56 & 1.11 & Middle \\
\hline 6 & 9 & I am satisfied with the cooperation of my family members & 3.55 & 1.13 & Middle \\
\hline 7 & 10 & I am satisfied with the support of my family members & 3.53 & 1.09 & Middle \\
\hline 8 & 13 & $\begin{array}{l}\text { I am satisfied with the degree to which my family members listen to each } \\
\text { other }\end{array}$ & 3.52 & 1.18 & Middle \\
\hline 9 & 6 & I am satisfied with how family members understand each other's feelings & 3.49 & 1.15 & Middle \\
\hline 10 & 4 & $\begin{array}{l}\text { I am satisfied with the consultation of my family members with important } \\
\text { decision }\end{array}$ & 3.46 & 1.09 & Middle \\
\hline 11 & 3 & I am satisfied with the ability and flexibility of my family to deal with others & 3.44 & 1.14 & Middle \\
\hline 12 & 8 & $\begin{array}{l}\text { I am satisfied with the expression of my family members about their love for } \\
\text { each other }\end{array}$ & 3.46 & 1.21 & Middle \\
\hline 13 & 16 & $\begin{array}{l}\text { I am satisfied that my family members have discussed the problems quietly } \\
\text { among themselves }\end{array}$ & 3.44 & 1.16 & Middle \\
\hline 14 & 5 & $\begin{array}{l}\text { I am satisfied that my family members discussed their ideas and beliefs } \\
\text { among themselves }\end{array}$ & 3.36 & 1.21 & Middle \\
\hline 15 & 12 & I am satisfied with the system within my family & 3.12 & 1.21 & Middle \\
\hline \multirow[t]{2}{*}{16} & 4 & I am satisfied with justice among my family members & 3.09 & 1.23 & Middle \\
\hline & & Total of satisfaction with Family life & 3.48 & 1.13 & Middle \\
\hline
\end{tabular}


Table 6 shows that the average ranged from 3.63 to 3.09, where the item No 15 which states that (I am satisfied with the time that my family members spend with each other) at the first rank with middle level and average 3.63, while item 4 which state that (I am satisfied with justice among my family members) at the last rank with middle level and average 3.09. The average of total of satisfaction with family life was 3.48 with middle level.

Second question: What is the level of the self-satisfaction of the Syrian refugees in Jordan?

To answer this question, the average and standard deviations were used for the level of self-satisfaction among Syrian refugees in Jordan. As shown in Table 7.

Table 7. The average and standard deviations for the level of self-satisfaction among Syrian refugees in Jordan descending according to the average

\begin{tabular}{|c|c|c|c|c|c|}
\hline Rank & No & Items & Average & Standard deviation & Level \\
\hline 1 & 11 & I am satisfied with the love and affection I offer to others & 3.66 & 1.02 & Middle \\
\hline 2 & 1 & I feel my life is going as required & 3.65 & 1.11 & Middle \\
\hline 3 & 10 & $\begin{array}{l}\text { I feel the confidence of others in my abilities and } \\
\text { potential }\end{array}$ & 3.63 & 1.21 & Middle \\
\hline 4 & 9 & $\begin{array}{l}\text { I am satisfied with my support for others to achieve their } \\
\text { goals }\end{array}$ & 3.61 & 1.04 & Middle \\
\hline 5 & 14 & I am better off than others & 3.60 & 1.12 & Middle \\
\hline 6 & 18 & I am satisfied with what I have achieved & 3.59 & 1.05 & Middle \\
\hline 7 & 13 & I am satisfied with my ability to deal with life conditions & 3.57 & 1.14 & Middle \\
\hline 8 & 12 & I feel optimistic even if something fails & 3.53 & 1.02 & Middle \\
\hline 9 & 4 & I am satisfied with my way of speaking to others & 3.50 & 1.00 & Middle \\
\hline 10 & 3 & I feel that my life is better than ever & 3.49 & 1.24 & Middle \\
\hline 11 & 5 & I feel that luck does not last for me most of the time & 3.47 & 1.10 & Middle \\
\hline 12 & 16 & I have no feel of disappointment & 3.44 & 1.08 & Middle \\
\hline 13 & 15 & I am satisfied to help others & 3.39 & 1.17 & Middle \\
\hline 14 & 17 & $\begin{array}{l}\text { I am satisfied with teaching the younger how to deal with } \\
\text { others }\end{array}$ & 3.35 & 1.04 & Middle \\
\hline 15 & 8 & I got things important in my life & 3.34 & 1.11 & Middle \\
\hline 16 & 7 & $\begin{array}{l}\text { I am satisfied with the solutions I give to others about the } \\
\text { problems }\end{array}$ & 3.31 & 1.09 & Middle \\
\hline 17 & 2 & $\begin{array}{l}\text { I am satisfied with my younger education how to make a } \\
\text { good decision }\end{array}$ & 3.29 & 1.03 & Middle \\
\hline 18 & & Total of self-satisfaction & 3.50 & 1.01 & Middle \\
\hline
\end{tabular}

Table 7 shows that the average ranged from 3.66 to 3.29, where the item No 11 which states that I am satisfied with the love and affection I offer to others at the first rank with middle level and average 3.66, while item 2 which state that I am satisfied with my younger education how to make a good decision at the last rank with middle level and average 3.29. The average of total of self-satisfaction was 3.50 with middle level.

Third question: Are there differences between the gender perceptions of Syrian refugees on the dimension of the scale of satisfaction with family life?

To find out if there were gender differences on the scale of satisfaction with family life, the $\mathrm{T}$ test was used. Table 8 shows the average, standard deviations and results of $\mathrm{T}$ test.

Table 8 . $T$ test results for the differences between the gender averages on satisfaction with family life scale

\begin{tabular}{llllll}
\hline scale & gender & average & standard deviation & T & Significance level \\
\hline Satisfaction with family life & Male & 3.01 & 1.02 & 7.46 & 0.000 \\
& Female & 3.27 & 0.89 & & \\
\hline
\end{tabular}

Table 8 shows that $\mathrm{T}$ value (7.46) and statistical value $(0.0001>\mathrm{p})$. In addition, the table shows that the female average is higher than male average.

Forth question: Are there differences between the gender perceptions of Syrian refugees on the dimension of the scale of self-satisfaction? 
To find out if there were gender differences on the scale of self-satisfaction life, the $\mathrm{T}$ test was used. Table 9 shows the average, standard deviations and results of $\mathrm{T}$ test.

Table 9. $\mathrm{T}$ test results for the differences between the gender averages on self-satisfaction scale

\begin{tabular}{llllll}
\hline scale & gender & average & standard deviation & T & Significance level \\
\hline Satisfaction with family life & Male & 3.11 & 1.12 & 6.52 & 0.000 \\
& Female & 3.48 & 0.04 & & \\
\hline
\end{tabular}

Table 9 shows that $\mathrm{T}$ value (6.52) and statistical value $(0.0001>\mathrm{p})$. In addition, the table shows that the female average is higher than male average.

Fifth question: Are there statistically significant differences at the level of significance $(0.05 \geq \alpha)$ of satisfaction with family life due to the age? To answer this question, One Way ANOVA analysis was used, as shown in Table 10.

Table 10. The results of One Way ANOVA analysis of the average estimates of Syrian refugees on the scale of satisfaction with family life due to the age

\begin{tabular}{lllllll}
\hline Variable & Source of variance & Sum of squares & $\mathrm{df}$ & Mean squares & (F) value & Statistical analysis \\
\hline satisfaction with family life & Between Groups & 1.247 & 3 & 0.416 & 8.415 & 0.000 \\
& Within Groups & 5.415 & 423 & 0.013 & & \\
& total & 6.662 & 426 & & & \\
\hline
\end{tabular}

Note. ${ }^{*}$ statistical significance at the level of significance $(\alpha \leq 0.05)$.

Table 10 shows the statistically significant differences in the level of statistical significance in the average estimates of Syrian refuges on the scale of satisfaction with family life according to the age. To identify the statistical significance of these differences, the Schiffe test was used for post-Hoc, as shown in Table 11.

Table 11. The results of Schiff test for the average estimates of Syrian refuges on the scale of satisfaction with family life according to the age

\begin{tabular}{lllllll}
\hline Scale & Age & Average & Less than 15 years & 16-30 years & $\begin{array}{l}31-45 \\
\text { years }\end{array}$ & More than 46 years \\
\hline Satisfaction with family life & Less than 15 years & 3.61 & 3.61 & 3.39 & 2.47 & 3.41 \\
& 16-30 year & 3.39 & & 0.12 & 0.06 & $* 0.68$ \\
& 31-45 year & 3.47 & & & 0.05 & 0.11 \\
& More than 46 years & 3.41 & & & & 0.01 \\
\hline
\end{tabular}

Note. *statistical significance at the level of significance $(\alpha \leq 0.05)$.

Table 11 shows statistically significant differences at $(\alpha \leq 0.05)$ between the averages of the refugee estimates on satisfaction with family life scale between who are less than 15 years, more than 46 years, in favor of less than 15.

Sixth question: Are there statistically significant differences at the level of significance $(0.05 \geq \alpha)$ of self-satisfaction due to the age?

Table 12. The results of One Way ANOVA analysis of the average estimates of Syrian refugees on the scale of self-satisfaction due to the age

\begin{tabular}{lllllll}
\hline Variable & Source of variance & Sum of squares & df & Mean squares & (F) value & Statistical analysis \\
\hline Self-satisfaction & Between Groups & 2.134 & 3 & 0.711 & 7.863 & 0.000 \\
& Within Groups & 4.986 & 423 & 0.012 & & \\
& total & 4.120 & 426 & & & \\
\hline
\end{tabular}

Note. *statistical significance at the level of significance $(\alpha \leq 0.05)$. 
Table 12 shows the statistically significant differences in the level of statistical significance in the average estimates of Syrian refuges on the scale of self-satisfaction according to the age. To identify the statistical significance of these differences, the Schiffe test was used for post-Hoc, as shown in Table 13.

Table 13. The results of Schiffe test for the average estimates of Syrian refuges on the scale of self-satisfaction according to the age

\begin{tabular}{lllllll}
\hline Scale & Age & Average & Less than 15 years & $16-30$ years & 31-45 years & More than 46 years \\
\hline Satisfaction with family life & Less than 15 years & 3.31 & 3.31 & 3.54 & 2.49 & 3.28 \\
& 16-30 years & 3.54 & & 0.11 & 0.04 & 0.09 \\
& 31-45 years & 3.49 & & & 0.13 & $* 0.32$ \\
& More than 46 years & 3.28 & & & $* 0.44$ & \\
\hline
\end{tabular}

Note. *statistical significance at the level of significance $(\alpha \leq 0.05)$

Table 13 shows statistically significant differences at $(\alpha \leq 0.05)$ between the averages of the refugee estimates on self-satisfaction scale between who are 16-30 years, 31-45 years, more than 46 years, in favor of 16-30 years, $31-45$ years.

\section{Results and Discussion}

The results indicate that there is an average level of satisfaction with family life and self-satisfaction. The researcher finds that refugees, like other individuals, are affected by the circumstances surrounding them such as emotional tension, frustration, disappointment and repression, the weakness of the higher ego, And the erroneous and unrealistic interpretation of traumatic experiences, and poor compatibility, which lead to reduced satisfaction with family life. In addition, the physiological and psychological components of the refugee individual are not very different from any other person in the world. The researcher pointed out that the magnitude of the pressures that faced them, which were the social isolation, and lack of means of treatment, and the vagueness of fate, affected in one way or another the psychological structure of them. The researcher also finds that the loss of the husband or wife or children creates in the family negative thinking reflected on their mood, and lead to depression and distress and the tendency to isolation and rejection of speech and loss of appetite, and may reach the refusal of food, and poor concentration and attention, and feeling very stressed, they are dominated by authoritarian ideas related to death and suicide. These causes and factors lead to low satisfaction with family life and self-satisfaction. Refugees share the same painful experiences, whether psychological or physical. The results showed that the level of satisfaction with family life and self-satisfaction was higher among females. The researcher attributed the high level of psychological well-being and psychological stability among female refugee females compared to males to the nature of the customs, traditions and culture prevailing in Syrian society. The females also have the ability to cope with difficult living and living conditions To build positive relationships with them, to respect their views and views, to develop a sense of responsibility towards members of society in particular, and towards humanity in general, and the ability to Take responsibility and duties and abide by them, and Jordanian families who are relatives of females were able to provide support and social support, which helped them psychologically adapt to new conditions of life. And that females have the ability to perceive and understand others' feelings accurately and better than others to respond flexibly to changes in their social environment, as well as to be able to build stable, balanced and effective social relationships, as well as social and emotional skills can contribute to improving the cognitive functions of individuals and develop and enrich them. The result of this study differs from that of Schnittler et al. (2017), which pointed to the absence of gender differences, and the Bernal and Arocena (2014) study, which noted gender differences in favor of males.

Family support for individuals younger than 15 years of age generates a sense of security, stability, tranquility and sound social relations as strengthening, stabilizing and strengthening processes aimed the well-being of the individual. Social stability is naturally the culmination of happiness and satisfaction for family life. And that family support increases happiness, provides an appreciation of positive emotions, and reduces the negative impact of external events. Social relations are generally the most important sources of happiness that a person needs daily in his or her working life with friends and at work, thereby providing himself with the happiness and psychological comfort that satisfies the satisfaction of family life.

The self-satisfaction of individuals aged 16-45 years is due to the expression of general satisfaction that is consistent or congruent between the expectations of the individual with the behavior of the other, and this satisfaction has many aspects, including the most important style, friends, income and leisure. The researcher 
also believes that they have the ability to delay and bear frustration, and the ability of the individual to establish relations with others, and bear the burden of relations with others of anxiety and frustration and problems. The researcher also believes that they have the ability to assess themselves for their psychological health and happiness in life, and they have the ability to adapt to the traumatic events and face them with sufficient psychological flexibility that enables them to pass safely and continue their lives in a balanced and natural, and thus feel positive and achievement, interaction, control and influence on the external environment, and the ability to control the expression of their motives, impulses and feelings, and this makes them happy and self-satisfaction. The outcome of this study is consistent with the Bernal and Arocena study (2014), which indicated differences in the level of satisfaction with family life due to age variance in favor of age 11-16 years. The result of this study differs with the study of Ramesh et al. (2013), which indicates that there is no correlation between age and self-satisfaction.

\section{Recommendations}

Depending on the results of the study and its interpretation, the researcher recommends the following:

1) Preparing and encouraging educational programs that encourage and support self-satisfaction because of its significant impact on the personality of individuals.

2) Refugee families should provide more opportunities for social interaction, communication and social relations, encourage their children to express their feelings of acceptance, and encourage their feelings of independence, self-reliance and freedom of expression whenever they can.

3) The need to find centers for family guidance whose objectives are to promote satisfaction of all kinds among refugee families and their children.

4) Expanding the role of the psychological guide in the Syrian schools to work out preventive and developmental remedial programs that develop and deal with cases of dissatisfaction among the children of these families.

5) Further studies in the future on other samples and new variables.

\section{References}

Al-Nabigha, B. (2012). Values as a sign of personal-social happiness in a sample of university students. Research published in the third annual conference of the Department of Psychology, Egypt.

Amnesty International (2015). Amnesty International Report 2014/2015: The State of Human Rights in the World. $\quad$ Retrieved November 21, 2017, from https://www.amnesty.org/download/Documents/POL1025522016ARABIC.PDF

Bernal, A., \& Arocena, F. (2014). Established satisfaction with family life scale factor in middle school and high school adolescents. Psicogente, 17(31), 226-240. https://doi.org/10.17081/psico.17.31.433

Blan, K. (2015). Theories of Counseling and Psychotherapy. Amman: Scientific Cyclone House.

Botha, F., \& Booysen, F. (2013). Family functioning and life satisfaction and happiness in South African households. Social Indicators Research, 119(1), 163-182. https://doi.org/10.1007/s11205-013-0485-6

Calderón, M., Naranjo, I., \& Felpeto, R. (2012). Self-satisfaction of the mean age woman and its relation to other factors of daily life. Revista Cubana de Ginecologíay Obstetricia, 38(2), 199-213.

Damra, J., \& Nassar, Y. (2014). The effect of the CBT model on trauma in reducing the symptoms of depression in a sample of war children. Studies in Educational Sciences, 41(1), 445-461.

Department of social development (2013). White paper on families. Pretoria: Department of Social Development.

Farooqi, S. (2012). Self-satisfaction: the ultimate goal of life. Retrieved November 21, 2017, from http://www.lifeandpsychology.com/2012/06/self-satisfaction-ultimate-goal-of-life.html

Fine Dictionary (2017). Satisfaction definitions. Retrieved November 21, 2017, from http://www.finedictionary.com/satisfaction.html

Freihat, M. (2017). The refugee crisis in Jordan: risks and opportunities. Retrieved November 21, 2017, from http://governance.arij.net/blog/

Guillén, R., Aliaga, K., Quispe, F., Nicolás, Y., Solís, R., Robles, Y., Valencia, E., Vargas, E., \& Vilchez, L. (2013). Adaptación de la Escala de Satisfacción Familiar por Adjetivos (ESFA) en universitarios de Lima metropolitana. Anales de Salud Mental, 27(2), 14-21. 
Habib, T. (2015). Complacency. Retrieved November 21, 2017, from http://3alyoum.com/article/63363

Hilger, J., Loerbroks, A., \& Diehl, K. (2017). Eating behaviour of university students in Germany: dietary intake, barriers to healthy eating and changes in eating behaviour since the time of matriculation. Appetite, 109, 100-107. https://doi.org/10.1016/j.appet.2016.11.016

Hsieh, C. (2016). Domain importance in subjective well-being measures. Soc. Indic. Res., 127, 777-792. https://doi.org/10.1007/s11205-015-0977-7

López-Ortega, M., Torres-Castro, S., \& Rosas-Carrasco, O. (2016). Psychometric properties of the Satisfaction with Life Scale (SWLS): secondary analysis of the Mexican Health and Aging Study. Health and Quality of Life, 14(1), 1-7. https://doi.org/10.1186/s12955-016-0573-9

Nua, S. (2013). Canadian family leisure, family functioning, and family satisfaction: A family perspective. Master thesis, Brigham Young University, USA.

Ogwo, A. (2013). Adolescent-parent relationship as perceived by younger and older adolescents. IFE PsychologIA, 21(3), 224-229.

Orkhan, O. (2014). Situation of Syrian refugees in neighboring countries: facts - results - proposals. Retrieved November 21, 2017, from https://www.alsouria.net/content/

Rahim, M., Ishak, I., Shafia, S., \& Shafiai, R. (2013). Factors influencing family life satisfaction among parents in Malaysia: The structural equation modeling approach (SEM). Journal of Humanities and Social Science, $17(4), 78-85$.

Ramalho, J., Lachal, J., Bucher-Maluschke, J., Moro, M., \& Revah-Levy, A. (2016). A qualitative study of the role of food in family relationships: an insight into the families of Brazilian obese adolescents using photo elicitation. Appetite, 96, 539-545. https://doi.org/10.1016/j.appet.2015.10.023

Ramesh, M., Sathian, B., Sinu, E., \& Kiranmai, S. (2013). Efficacy of Rajayoga meditation on positive thinking: An index for self-satisfaction and happiness in life. Journal of Clinical and Diagnostic Research, 7(10), 2265-2267.

Rifai, L. (2017). Including not met. Syrian women and the search for the remains of a family. Retrieved November https://www.theguardian.com/world/2016/jan/09/my-syrian-refugee-lodger-helen-pidd

Roman et al. (2016). Relational aspects of family functioning and family satisfaction with a sample of families in the Western Cape. Social Work, 52(3), 302-312. https://doi.org/10.15270/52-3-511

Rözer, J., Mollenhorst, G., \& Poortman, A. (2016). Family and friends: Which types of personal relationships go together in a network? Soc. Indic. Res., 127, 809-826. https://doi.org/10.1007/s11205-015-0987-5

Ryff, C., \& Singer, B. (2013). Know thyself and become what you are: a eudemonic approach to psychological well-being. Journal of Happiness Studies, 9, 13-39. https://doi.org/10.1007/s10902-006-9019-0

Schnettler, B., Miranda-Zapata, E., Grunert, K., Lobos, G., Denegri, M., Hueche, C., \& Poblete, H. (2017). Life satisfaction of university students in relation to family and food in a developing country. Front Psychol, 8, 1522-1534. https://doi.org/10.3389/fpsyg.2017.01522

Taşdelen-Karçkay, A. (2016). Family Life Satisfaction Scale—Turkish version: Psychometric evaluation. Social Behavior \& Personality: An International Journal, 44, 631-640. https://doi.org/10.2224/sbp.2016.44.4.631

Thomson, K., Schonert-Reichl, K., \& Oberle, E. (2015). Optimism in early adolescence: relations to individual characteristics and ecological assets in families, schools, and neighborhoods. J. Happ. Stud., 16, 889-913. https://doi.org/10.1007/s10902-014-9539-y

United Nations High Commissioner for Refugees - UNHCR. (2015). Syria Regional Refugees in Jordan. Retrieved November 21, 2017, from https://www.UNHCR.com/html

United Nations High Commissioner for Refugees (UNHCR). (2013). The future of Syria the crisis of refugee children. Report of November 2013.

Zabriskie, R., \& Ward, P. (2013). Satisfaction with Family Life Scale. Marriage \& Family Review, 49(5), 446463. https://doi.org/10.1080/01494929.2013.768321

Zhao, H., Xu, Y., Wang, F., Jiang, J., \& Zhang, X. (2015). Influence of parent adolescent conflict frequency on adolescent family satisfaction and self-satisfaction in China: conflict coping tactics as moderators. 
Psychological Reports: Relationships \& Communications, $117(3), \quad 897-915$. https://doi.org/10.2466/21.10.PR0.117c28z7

\section{Copyrights}

Copyright for this article is retained by the author, with first publication rights granted to the journal.

This is an open-access article distributed under the terms and conditions of the Creative Commons Attribution license (http://creativecommons.org/licenses/by/4.0/). 